\title{
Improved Admixture Vaccine of Fentanyl and Heroin Hapten Immunoconjugates: Antinociceptive Evaluation of Fentanyl- Contaminated Heroin
}

\author{
Candy S. Hwang, ${ }^{\dagger, \S_{\odot}}$ Lauren C. Smith, ${ }^{\dagger, \ddagger \odot}$ Yoshihiro Natori, $^{\dagger, \|}$ Beverly Ellis, $^{\dagger}$ Bin Zhou, $^{\dagger}$
} and Kim D. Janda*, ${ }^{*}$

${ }^{\dagger}$ Departments of Chemistry, Immunology and Microbial Science, Skaggs Institute for Chemical Biology, and ${ }^{\star}$ Department of Neuroscience, The Scripps Research Institute, 10550 N Torrey Pines Rd, La Jolla, California 92037 United States

\section{Supporting Information}

ABSTRACT: Fentanyl and its derivatives have become pervasive contaminants in the U.S. heroin supply. Previously, we reported a proof-of-concept vaccine designed to combat against heroin contaminated with fentanyl. Herein, we optimized the admixture vaccine and found that it surpassed the individual vaccines in every antinociceptive test, including a $10 \%$ fentanyl to heroin formulation. It is anticipated that other co-occurring drug abuse disorders may also be examined with admixture vaccines.
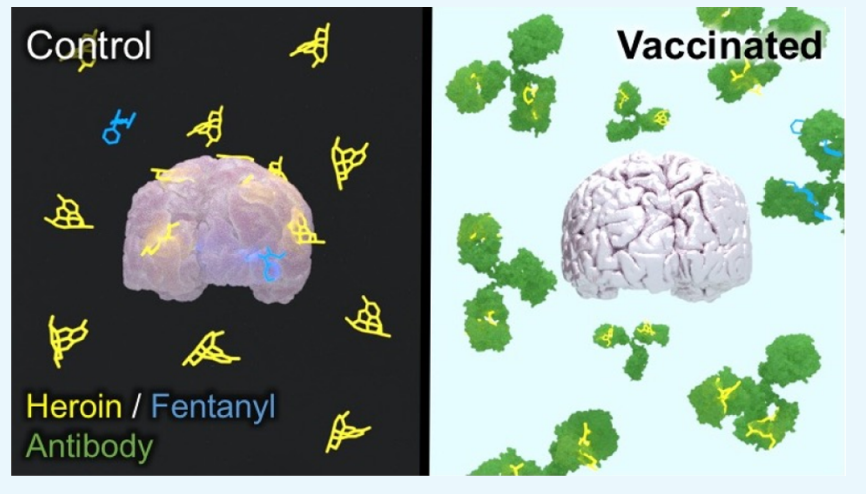

\section{INTRODUCTION}

The opioid use disorder is a significant public health concern. Although the number of opioid users in the U.S. has remained relatively constant over the past decade, there have been a mounting number of opioid overdose deaths, and as a result, a public health emergency was declared in $2017 .{ }^{1,2}$ Heroin is a schedule I, highly addictive opioid drug, which has garnered much attention recently because of the growing trend in drug poisoning deaths, which increased by $248 \%$ from 2011 to 2014. ${ }^{3}$ The increase in heroin overdose deaths has been attributed to unintentional intoxication involving synthetically manufactured drugs such as fentanyl and carfentanil. Illicit fentanyl usage is becoming an emerging threat most likely because of its inexpensive cost of production and greater potency than other opioids, including heroin and oxycodone. In utilizing fentanyl, a dealer may deliver the same drug payload for a fraction of the cost of heroin. The extreme potency of fentanyl gives rise to the issue of proper dosing, wherein a few milligrams can differentiate between the user experiencing euphoria or lethal intoxication. Since 2013, overdose deaths from fentanyl and other synthetic opioids have increased 6-fold, outstripping those from every other drug. ${ }^{3}$ Of increasing concern, fentanyl is now appearing as a common contaminant in other illicit drugs because of its potency and becoming one of the most prominent killers linked to the drug crisis of the nation. ${ }^{4,5}$

Hypoxia resulting from respiratory depression is the primary cause of lethality in opioid-induced overdose cases, most often involving intravenous (iv) heroin use. In a recent study examining the extracellular oxygen levels in the brains of rats receiving heroin laced with $10 \%$ fentanyl, brain hypoxia was greatly enhanced when compared to heroin or fentanyl alone. ${ }^{6}$ This finding suggests that the accidental exposure to fentanyl, even in the presence of heroin as a minor contaminant, puts the users at a significant risk for overdose and further severe health complications. ${ }^{6}$ Naloxone is the principal treatment for opioid overdose reversal, whereas buprenorphine and methadone are the traditional medications for addiction recovery. Although naloxone has proven indispensable in the wake of the developing opioid epidemic, the traditional pharmacotherapy suffers from several drawbacks such as a short half-life and undesirable side effects such as dysphoria. ${ }^{7}$ Current long-term addiction therapies also suffer from limitations including side effects and accessibility issues, as well as incidents of relapse occurring for about $33 \%$ of patients. ${ }^{8,9}$

We and other research groups have previously reported several examples of immunopharmacotherapy as an innovative treatment strategy for addiction. The concept behind immunopharmacotherapy is that it provides immunoantagonistic protection from the drug without binding to the drug receptors in the central nervous system (CNS). ${ }^{10-19}$ Moreover, antidrug vaccines produce a long-lasting guard against the target drug without many of the side effects associated with traditional pharmacological therapies. Individual conjugate

Received: June 27, 2018

Accepted: September 7, 2018

Published: September 20, 2018 
vaccines of heroin ${ }^{13,16,20-22}$ and fentanyl ${ }^{11}$ have been previously disclosed. Yet, admixture haptenic vaccines are uncommon. There is one report of an admixture vaccine examining the structurally congruent opioids, morphine and oxycodone immunoconjugates, ${ }^{15}$ and our own disclosure of a heroin-fentanyl vaccine. ${ }^{23}$ Importantly, in our previous proofof-concept study, our admixture vaccine exhibited a similar level of efficacy when compared to each individual conjugate vaccine. Herein, we detail an improved admixture immunization strategy through an increasing hapten copy number and employing a superior carrier protein, tetanus toxoid (TT), and then combining two individual immunoconjugate vaccines to target heroin and fentanyl (Figure 1).

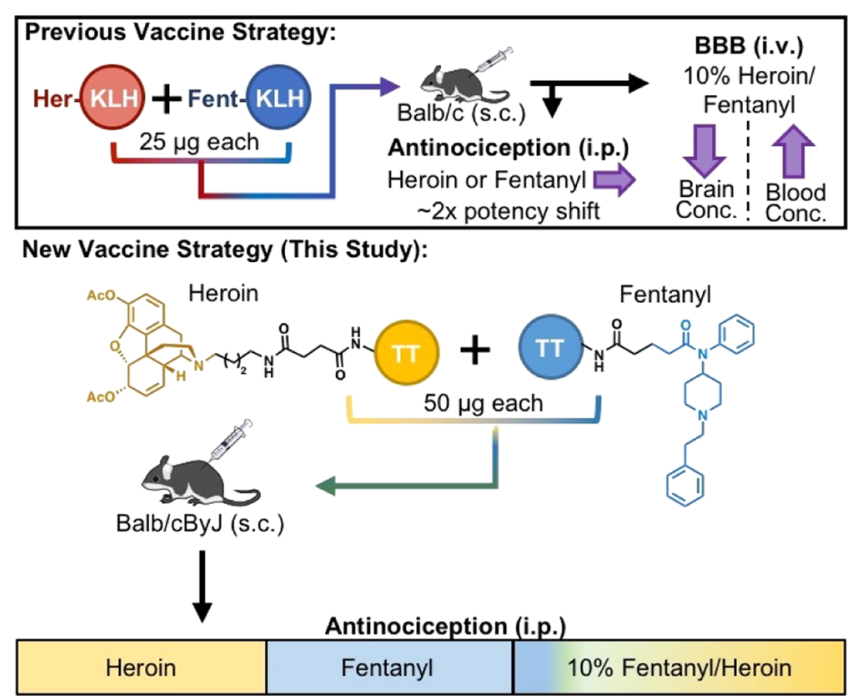

Figure 1. Illustration of the two admixture vaccination strategies. Fentanyl and heroin are highlighted in blue and yellow, respectively, with hapten linkers depicted in black. BBB stands for blood-brain barrier experiments; KLH stands for keyhole limpet hemocyanin; sc stands for subcutaneous injection; and ip stands for intraperitoneal injection.

\section{RESULTS AND DISCUSSION}

Extending our immunopharmacotherapy approach from heroin to the fentanyl class of drugs was a necessary transition in our vaccine work considering the increase of opioid overdose from synthetic adulterants, which is contributing to the rise in drug deaths across the U.S. As the frequency of fentanyl contamination appearing in heroin and other drug samples continues to grow at alarming rates, we were greatly interested in improving upon our proof-of-concept admixture vaccine (Figure 1).

The amount of immunogenic carrier protein (T-cell epitope, $100 \mu \mathrm{g})$ used in each vaccine was kept constant to stimulate an equivalent adaptive immune response (Table 1). However, because of the prohibitive cost of TT $(\$ 500 / \mathrm{mg})$ compared to keyhole limpet hemocyanin ( $\mathrm{KLH}, \$ 2.27 / \mathrm{mg}$ ), we opted to use $100 \mu \mathrm{g}$ of $\mathrm{KLH}$ in the control group as a representative of immunogenic carrier protein rather than TT itself. In our previous report, the individual vaccine groups received $50 \mu \mathrm{g}$ of the immunoconjugate, whereas the admixture group received $25 \mu \mathrm{g}$ of each immunoconjugate. ${ }^{23}$ For this study, we utilized TT, a superior carrier protein to $\mathrm{KLH}^{24}$ and altered conjugation parameters to increase the copy numbers
Table 1. Vaccine Schedule and Formulation Parameters for Immunoconjugates $^{a}$

\begin{tabular}{|c|c|c|}
\hline $\begin{array}{l}\text { Vaccination } \\
\text { Group }\end{array}$ & $\begin{array}{l}\text { Immunoconjugate } \\
(\mu \mathrm{g} / \text { dose })\end{array}$ & $\begin{array}{c}\text { Antinoc. Drug } \\
\text { ( } n=6 \text { per group) }\end{array}$ \\
\hline $\begin{array}{c}\text { Fent } \\
(n=12)\end{array}$ & $\begin{array}{c}50 \mu \mathrm{g} \text { Fent-TT } \\
+50 \mu \mathrm{g} \mathrm{TT}\end{array}$ & $\begin{array}{c}\text { Fentanyl } \\
10 \% \text { Fentanyl/ } \\
\text { Heroin }\end{array}$ \\
\hline $\begin{array}{l}\text { Her } \\
(n=12)\end{array}$ & $\begin{array}{l}50 \mu \mathrm{g} \mathrm{Her-TT} \\
+50 \mu \mathrm{g} \mathrm{TT}\end{array}$ & $\begin{array}{c}\text { Heroin } \\
10 \% \text { Fentanyl/ } \\
\text { Heroin }\end{array}$ \\
\hline $\begin{array}{l}\text { Fent }+ \text { Her } \\
\quad(n=18)\end{array}$ & $\begin{array}{l}50 \mu \mathrm{g} \text { Fent-TT } \\
+50 \mu \mathrm{g} \text { Her-TT }\end{array}$ & $\begin{array}{c}\text { Fentanyl } \\
\text { Heroin } \\
10 \% \text { Fentanyl/ } \\
\text { Heroin } \\
\end{array}$ \\
\hline $\begin{array}{l}\text { Control } \\
(n=18)\end{array}$ & $100 \mu \mathrm{g} \mathrm{KLH}$ & $\begin{array}{c}\text { Fentanyl } \\
\text { Heroin } \\
10 \% \text { Fentanyl/ } \\
\text { Heroin }\end{array}$ \\
\hline \multicolumn{3}{|c|}{$\begin{array}{l}\text { Adjuvants: } \mathrm{CpG}-50 \mu \mathrm{g} / \mathrm{dose} \text {, Alum }-0.8 \mathrm{mg} / \mathrm{dose} \\
\text { Conjugation Numbers: Fent-BSA }-23.4, \mathrm{Her}-\mathrm{BSA}-12.4\end{array}$} \\
\hline Timeline: & $\begin{array}{ll}3 & 4 \\
\text { Week }\end{array}$ & 6 \\
\hline
\end{tabular}

${ }^{a} \mathrm{CpG}$ stands for cytosine-phosphodiester-guanine oligodeoxynucleotide (ODN) 1826, a class-B-type CpG adjuvant for rodents. Alum stands for alhydrogel. Conjugation number refers to the number of hapten copy numbers on bovine serum albumin (BSA) as a surrogate for TT during conjugation conditions. Antinoc. stands for antinociception assays.

of the immunoconjugates from 11.3 for Fent and 7.3 for Her to 23.4 and 12.4 , respectively. ${ }^{23}$ In addition, we doubled the number of rodents in the individual vaccine groups and increased the number of animals in the control and admixture groups by $33 \%$ from the previous study. Finally, mice were vaccinated subcutaneously according to the schedule given in Table 1.

The sera collected from mice at weeks 3 and 5 were analyzed against both Her-BSA and Fent-BSA to determine the level of anti-heroin or anti-fentanyl $\operatorname{IgG}$ antibodies produced by each vaccine group (Table 2). Accordingly, each individual serum sample was examined using enzyme-linked immunosorbent assay (ELISA), while midpoint titer was averaged per vaccination group and coating antigen for each bleed time point. Although, the Fent vaccination group had modest titers at week 3, the polyclonal antibody response improved over time with subsequent boosts. Both individual vaccines were within the same midpoint titer range by week 5 . Moreover, the admixture vaccination group elicited the highest level of response at week 5 .

The ELISA data were analyzed using a one-way analysis of variance (ANOVA) with a Dunnett's multiple comparison test (Table 2). At week 3, $[F(3,55)=25.07, P<0.0001]$, the admixture was significantly different when compared to the control when Her-BSA was used as the coating antigen. Both the Fent-TT and the admixture vaccines were significant compared to the control when Fent-BSA was used as the coating antigen at week $3[F(3,55)=40.36, P<0.0001]$. At week 5 , the same trends were observed for Her-BSA $[F(5,53)$ $=24.49, P<0.0001]$ and Fent-BSA $[F(3,54)=22.08, P<$ $0.0001]$. In agreement with the ELISA data, the affinity for the 
Table 2. Midpoint Titers and $\mathrm{IC}_{50}$ Values by ELISA and SPR, Respectively

\begin{tabular}{|c|c|c|c|c|c|c|}
\hline \multirow[b]{2}{*}{ vaccination group } & \multirow[b]{2}{*}{ antigen } & \multicolumn{2}{|c|}{ midpoint titers $^{a}$} & \multirow[b]{2}{*}{ analyte } & \multicolumn{2}{|c|}{$\mathrm{IC}_{50}^{b}(\mathrm{nM})$} \\
\hline & & week 3 & week 5 & & week 3 & week 5 \\
\hline \multirow[t]{2}{*}{ Fent } & Her-BSA & $175 \pm 87$ & $509 \pm 154$ & 6-AM ${ }^{c}$ & & \\
\hline & Fent-BSA & $541 \pm 80^{+\neq}$ & $4614 \pm 1186^{\ddagger}$ & fentanyl & $344(232-511)$ & $71(60-84)$ \\
\hline \multirow[t]{2}{*}{ Her } & Her-BSA & $3378 \pm 1543$ & $4732 \pm 714$ & $6-\mathrm{AM}^{d}$ & $121(105-139)$ & $46(43-50)$ \\
\hline & Fent-BSA & $49 \pm 10$ & $28 \pm 6$ & fentanyl ${ }^{c}$ & & \\
\hline \multirow[t]{2}{*}{ Fent + Her } & Her-BSA & $12903 \pm 1918^{* * * * * *}$ & $18483 \pm 3129 * * * *$ & 6-AM ${ }^{d}$ & $201(149-289)$ & $76(48-121)$ \\
\hline & Fent-BSA & $1380 \pm 171^{+千+t}$ & $10098 \pm 1661^{\text {錁 }}$ & fentanyl & $124(59-259)$ & $77(47-126)$ \\
\hline \multirow[t]{2}{*}{ control } & Her-BSA & $23 \pm 4$ & $14 \pm 7$ & 6- $\mathrm{AM}^{d}$ & n.d..$^{e}$ & n.d. ${ }^{e}$ \\
\hline & Fent-BSA & $45 \pm 7$ & $11 \pm 3$ & fentanyl & n.d. ${ }^{e}$ & n.d. ${ }^{e}$ \\
\hline
\end{tabular}

${ }^{a}$ Midpoint titers are reported as means \pm standard error of the mean. ${ }^{b} \mathrm{IC}_{50}$ values are reported as means, and $95 \%$ confidence intervals are given in parentheses in nanomolar. ${ }^{c} 6$-AM and fentanyl were not run for Fent-TT and Her-TT vaccination groups, respectively. ${ }^{d} 6$-AM was the primary analyte used in the SPR studies because of its longer half-life at $\mathrm{pH} 7.4$ at room temperature compared to heroin. ${ }^{e}$ Control vaccine groups were run by SPR but did not converge because of lack of detected antibody binding. Significance is denoted by an asterisk (for Her-BSA as the coating antigen) or double dagger (for Fent-BSA as the coating antigen) for midpoint titer from a one-way ANOVA and a Dunnett's post hoc test when comparing vaccinated groups to controls. $* * * P \leq 0.001 ; * P<0.05 ; \$+\$ P \leq 0.001$ vs control.

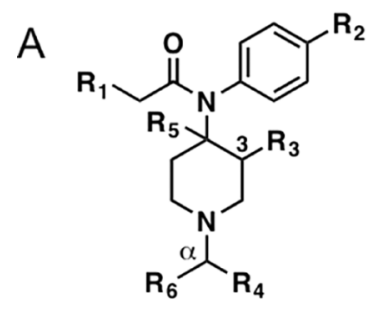

J. Carfentanil: $R_{1}=M e, R_{5}=C O O M e, R_{6}=B n$
Unspecified $R$ Groups $=H$

A. Fentanyl hapten: $\mathrm{R}_{1}=\left(\mathrm{CH}_{2}\right)_{2} \mathrm{COOH}, \mathrm{R}_{6}=\mathrm{Bn}$

B. Fentanyl: $R_{1}=\mathrm{Me}, \mathrm{R}_{6}=\mathrm{Bn}$

C. Acetylfentanyl: $\mathrm{R}_{1}=\mathrm{H}, \mathrm{R}_{6}=\mathrm{Bn}$

D. Butylfentanyl: $\mathrm{R}_{1}=\mathrm{Pr}, \mathrm{R}_{6}=\mathrm{Bn}$

E. Tolylfentanyl: $R_{1}=M e, R_{2}=M e, R_{6}=B n$

F. 3-Methylfentanyl: $R_{1}=M e, R_{3}=M e, R_{6}=B n$

G. $\alpha$-Methylfentanyl: $R_{1}=M e, R_{4}=M e, R_{6}=B n$

H. Alfentanil: $\mathrm{R}_{5}=\mathrm{CH}_{2} \mathrm{OMe}, \mathrm{R}_{6}=-\xi$

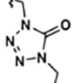

${ }^{\mathrm{N}-\mathrm{N}}>$

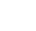

\begin{tabular}{|c|c|c|}
\hline \multirow[b]{2}{*}{ Derivative } & \multicolumn{2}{|c|}{$\mathrm{IC}_{50}(\mathrm{nM})$} \\
\hline & Fent & Fent + Her \\
\hline $\mathrm{B}$ & $71(60-84)$ & $77(47-126)$ \\
\hline $\mathrm{C}$ & $26(22-30)$ & $8(7-10)$ \\
\hline D & $21(19-24)$ & $11(6-19)$ \\
\hline$E$ & $153(109-214)$ & $87(56-134)$ \\
\hline $\mathrm{F}$ & $887(556-1414)$ & $539(246-1178)$ \\
\hline $\mathbf{G}$ & $39(27-56)$ & $64(23-180)$ \\
\hline $\mathrm{H}$ & $\gg 100 \mu \mathrm{M}$ & $\gg>100 \mu \mathrm{M}$ \\
\hline $\mathrm{I}$ & $>1 \mu \mathrm{M}$ & $>100 \mu \mathrm{M}$ \\
\hline$J$ & $155(108-221)$ & $321(147-701)$ \\
\hline
\end{tabular}

Figure 2. Calculated $\mathrm{IC}_{50}$ values for fentanyl and related analogues by SPR from week 5 bleeds. (A) Structures are given on the left of each fentanyl-related analogue, and $(\mathrm{B}) \mathrm{IC}_{50}$ values $(\mathrm{nM})$ with respective $95 \%$ confidence intervals given in nanomolar are reported on the right.

drug improves with subsequent vaccination boosts (Table 2). The $\mathrm{IC}_{50}$ values were obtained by pooling the individual sera from each vaccine group, and all groups were analyzed by a competitive binding assay using surface plasmon resonance (SPR).

After determining the relative midpoint titer and affinity for each vaccine group, we were interested in the efficacy of the Fent and admixture vaccines in protecting against additional analogues of fentanyl that may also appear as adulterants (Figure 2). Eight analogues of fentanyl were tested against antibodies from week 5 sera. Four of the eight analogues bind as competitively or better than fentanyl (derivatives C, D, E, and G, respectively, Figure 2). Carfentanil and 3-methylfentanyl exhibit sub-micromolar affinity (derivative $\mathrm{J}$ and $\mathrm{F}$, respectively), whereas alfentanil and remifentanil are not well recognized by the antibodies (derivatives $\mathrm{H}$ and $\mathrm{I}$, respectively, Figure 2). Interestingly, although 3-methylfentanyl and $\alpha$ methylfentanyl are regioisomers with small methyl substitutions (derivatives F and G, respectively, Figure 2), a simple methyl functionalization at the $\mathrm{C} 3$-position of the piperidine ring imparts a greater perturbation to antibody recognition than the methyl substitution alpha to the piperidine nitrogen.

Following thorough characterization of each vaccine, we then tested their efficacy in vivo. Hot plate and tail flick nociception is mediated in the CNS and provides a relevant behavioral model of the ability of the vaccine to reduce drug access to brain and its subsequent effects; therefore, it was used as a substitute for drug reward in the current study. For these behavioral models, we employed heroin, fentanyl, and a $10 \%$ fentanyl to heroin antinociception assay to test the vaccine efficacy against all the three drug scenarios. Although "street heroin" has variable amounts of fentanyl contamination, it would be impractical to test every possible variation. Therefore, we selected $10 \%$ fentanyl to heroin as a representative adulterant ratio for several reasons: (1) the first and most notorious brand of "street heroin" known as "Tango and Cash" was found to contain approximately $12 \%$ fentanyl, which was thought to be responsible for approximately 126 overdose deaths. ${ }^{25}$ (2) Investigators in Melbourne, Australia, recently analyzed the postmortem blood samples of victims who overdosed fentanyl-laced heroin. Importantly, a range of blood ratios of fentanyl to morphine from 1.25 to $19 \%$ with an average ratio of $10.21 \%$ were found. ${ }^{26}$ (3) As previously discussed, vide supra, investigators who studied the markers of respiratory depression used a mixture of heroin contaminated with $10 \%$ fentanyl (iv) in rats and found that brain hypoxia was potentiated by the mixture compared to pure heroin or fentanyl. ${ }^{6}$ On the basis of these findings, it was deemed that a $10 \%$ fentanyl to heroin contamination would be an adequate grounding for our behavioral antinociception studies.

In order to carry out such an experiment, we kept the fentanyl dosing range constant and modified the heroin doses to be 10-fold larger than the fentanyl dose. Organization and testing of each vaccination group are described in Table 1, with six mice per group per drug scenario. The positive control 


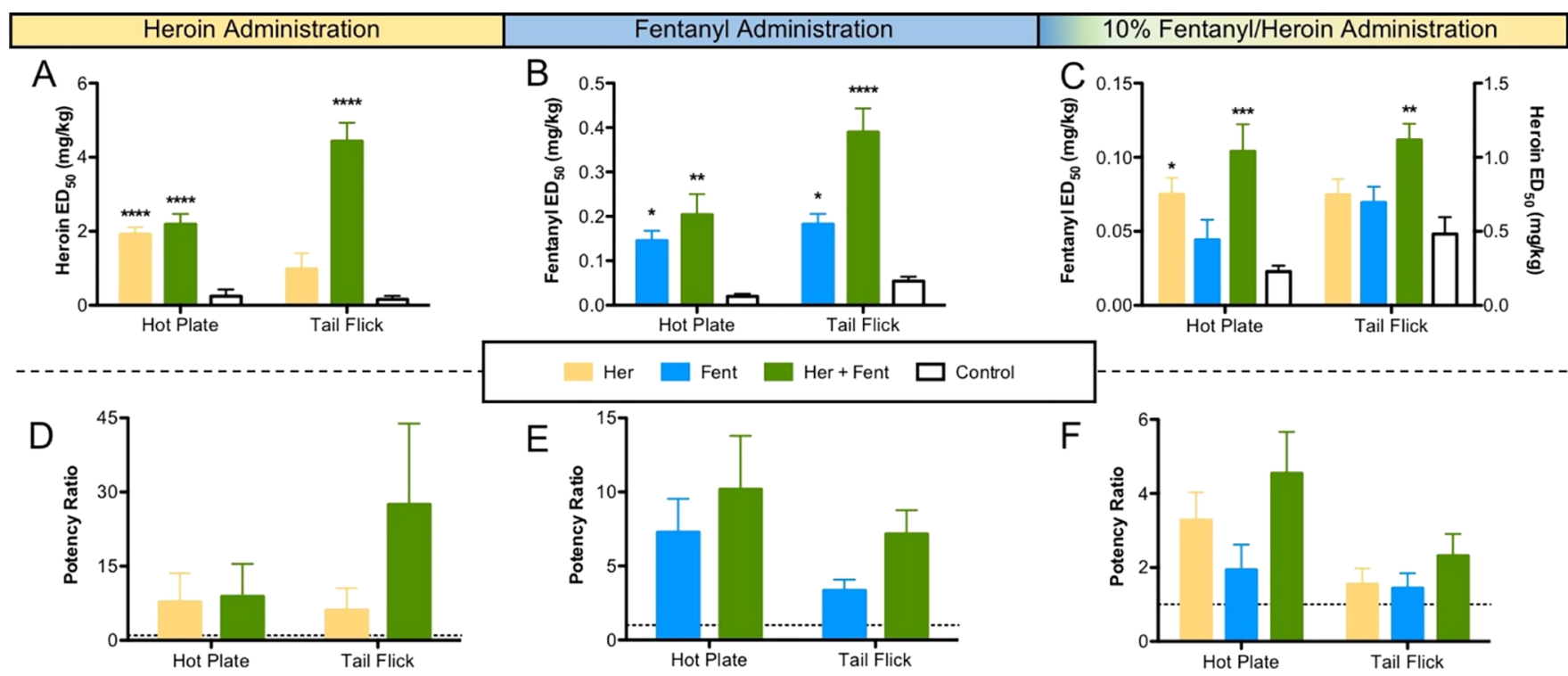

Figure 3. Testing the efficacy of admixture vaccines against heroin, fentanyl, and a combination of drug (ip) in mice. The inset panel describes each vaccination group. (A) Results from hot plate and tail flick antinociceptive tests using heroin. (B) Results from antinociceptive tests using fentanyl. (C) Results from antinociceptive tests using 10\% fentanyl in heroin. (D) Potency ratios for vaccine groups against heroin. (E) Potency ratios for vaccine groups against fentanyl. (F) Potency ratios for vaccine groups against a $10 \%$ mixture of fentanyl in heroin. Significance is denoted by an asterisk from a one-way ANOVA and a Dunnett's post hoc test when comparing vaccinated groups to controls. $* * P \leq 0.01, * * * P \leq 0.001, * * * * P$ $\leq 0.0001$ vs control. The dashed lines in the potency panels denote the control levels.

groups Her and Fent were run using only their respective drug tests and the combination to minimize the number of animals used during testing. The dose at which half of the animals in a group experience the full antinociceptive effect of the drug $\left[100 \%\right.$ maximum possible effect (MPE)] is defined as the $\mathrm{ED}_{50}$ value. The potency ratios were calculated by normalizing the vaccine-shifted $\mathrm{ED}_{50}$ value compared to the control (KLHvaccinated) values in each antinociceptive test (Figure 3 ).

Results are shown in Figure 3 for each test with the $\mathrm{ED}_{50}$ values reported on the top and the potency ratios on the bottom, whereas the individual dose-response curves are provided in the Supporting Information (Figures S7-S9). Thus, when heroin was administered in the antinociception assay, both the Her and the Her + Fent admixture vaccines significantly protected the mice compared to controls based on a one-way ANOVA $[F(2,14)=26.01, P<0.0001$, hot plate; $F(2,14)=36.99, P<0.0001$, tail-flick $]$; however, the Her group was only significantly different from the control group in the hot plate assay. With fentanyl administration, Fent and Her + Fent admixture also blunted drug effects compared to control mice vaccinated with $\mathrm{KLH}$, cytosine-phosphodiesterguanine $(\mathrm{CpG})$ ODN, and alum [one-way ANOVA, $F(2,15)=$ 9.986, $P=0.0017$, hot plate; $F(2,15)=25.10, P<0.0001$, tail flick]. In the combined drug antinociceptive test, only the Her + Fent admixture vaccines were efficacious against the combination in both assays according to a one-way ANOVA $[F(3,20)=7.787, P=0.0012$, hot plate; $F(3,20)=5.881, P=$ 0.0048 , tail flick].

The Her vaccine group presented a greater significance in the hot plate assay compared to the fentanyl vaccine (Figure $3)$. Moreover, the dosing of fentanyl was kept the same $(0.05$ $\mathrm{mg} / \mathrm{kg}$ ), whereas the initial dose of heroin was reduced from 2 to $0.5 \mathrm{mg} / \mathrm{kg}$. Indeed, this stepwise incremental order is consistently observed in both assays when using the $10 \%$ antinociception dosing, with the least efficacious group being control, followed by Fent, Her, and the most effective being
Her + Fent. In all tests, the admixture performed appreciably better than individual vaccines and significantly better in both antinociception tests, indicating a superior performance of the admixture vaccine.

A caveat to our admixture antinociception testing was being restricted to intraperitoneal (ip) drug administration versus iv, the latter of which would undoubtedly better mirror the reallife scenarios. However, this constraint was unavoidable as in a murine model, the maximal doses are limited to $200 \mu \mathrm{L}$ through iv administration. In addition, cumulative dosing is not an option for either route of iv administration (retro-orbital sinus or tail vein). By contrast, ip administration allows for 0.8 $\mathrm{mL}$ to $3.2 \mathrm{~mL}$ of heroin/fentanyl solution to be dispensed, which enables both cumulative dosing and more accurate administration of concentrations $(5 \mathrm{~mL} / \mathrm{kg})$.

A second provision to our admixture vaccine testing was that the individual vaccines were constructed with $50 \mu \mathrm{g}$ of unconjugated TT. Although adding the unconjugated TT to individual vaccines was meant to control for the total $\mathrm{T}$-cell epitope within each vaccine group, the unconjugated $\mathrm{TT}$, a potent microbial antigen, may have created unwanted competition between the antibody response for antidrug and anti-TT antibodies, overall reducing the amount of antidrug neutralizing antibodies. In fact, this suspicion corroborated with the ELISA data (Table 2), which show substantially lower titers when compared to the admixture, despite employing the same amount of the immunoconjugate. The titers suggest that the antibodies were competitively raised against the $50 \mu \mathrm{g}$ of "blank" TT.

To further delve into these findings, an ELISA was run against blank TT as a coating antigen to measure the polyclonal antibody response to the carrier protein in each vaccination group for both bleed time points (Supporting Information, Figure S10). In alignment with our hypothesis, titers from week 3 show that the individual vaccines elicit higher anti-TT titers than the admixture vaccine compared to 
control [one-way ANOVA, $F(3,54)=5.483, P=0.0023$, Supporting Information, Figure S10, week 3]. However, by week 5 , there was no significant difference found between any of the individual and admixture vaccines [one-way ANOVA, $F(3,54)=7.645, P=0.0002$, Supporting Information, Figure S10, week 5]. As expected, control mice did not produce detectible anti-TT titers at either bleed time point. In sum, we posit that excess unconjugated TT provides unwanted TT immunogenicity early on; yet, this is ultimately subdued because of tolerance upon continued boosting.

The first measure to improve the efficacy of our admixture vaccine was implementation of the superior carrier protein, TT, over KLH. Our lab has repeatedly demonstrated that the use of $\mathrm{TT}$ as a carrier protein provides improved efficacy over other carrier proteins for several of our vaccines against drugs of abuse including nicotine, cocaine, and oxycodone. ${ }^{14,27,28}$ Increasing hapten densities on TT has been proven to empirically increase the efficacy in heroin vaccines; however, this trend was not observed for the carrier protein $\mathrm{KLH}^{17}$ Therefore, maximizing the hapten conjugation for both Her and Fent was the second measure to improve upon our initial proof-of-concept admixture vaccine. Our rationale for lower copy numbers in the proof-of-concept vaccine study was to have comparable copy numbers for Fent-KLH and Her-KLH, so conjugation time and copy number were carefully monitored and controlled. ${ }^{23}$ By allowing the haptens to conjugate with carrier protein for an extended period of time $(20 \mathrm{~h})$, the hapten density was increased 1.7 -fold and 2-fold for Her and Fent immunoconjugates, respectively. Both carrier protein and hapten density modifications drastically improved the performance of the admixture vaccine compared to their individual component vaccines.

To summarize, an admixture vaccine was assembled to combat what has become to be known as "street heroin," heroin adulterated with the potent synthetic opioid fentanyl. On the basis of our preliminary findings, an opioid vaccine cocktail containing structurally incongruent immunoconjugates can be readily applied to target two different drug species. The admixture vaccine appeared to sequester both drugs and performed exceptionally well in antinociception animal models in comparison to our individual drug vaccines. Future plans will be to expand this combination strategy to additional nonopioid drugs, such as cocaine. ${ }^{4}$ Indeed, individuals with cooccurring cocaine and opioid use disorders have more severe drug use and poorer substance use treatment outcomes compared with individuals with either substance user disorder. Lastly, admixture vaccines may provide a future therapy to protect against the accidental exposure to other fentanylcontaminated drugs.

\section{EXPERIMENTAL SECTION}

Animals. Immunization and blood collection were performed as detailed in our previous study with the following differences. $^{23}$ Female Balb/cByJ (Taconic Farms, Germantown, NY) were vaccinated subcutaneously (sc) with $100 \mu \mathrm{g}$ of the immunoconjugate. The details of the schedule of experiments and vaccination are listed in Table 1 . Mice were bled on days 24 and 38 by submandibular puncture with a single-use lancet to collect $100-500 \mu \mathrm{L}$ of whole blood. Each group was composed of either 12 or 18 mice. The mice were weighed weekly, and any injection site reaction was measured on the day of behavioral testing (Figures S5 and S6, respectively). The mice were group-housed in an AAALAC- accredited vivarium. All animal care and experimental procedures adhered to the guidelines of the National Institutes of Health Guide for the Care and Use of Laboratory Animals, and experimental protocols were approved by the Institutional Animal Care and Use Committee of The Scripps Research Institute.

Preparation, Formulation, and Administration of Vaccine. Fentanyl was acquired from Sigma-Aldrich, and heroin was provided by NIDA. Heroin is soluble in bacteriostatic $0.9 \% \mathrm{NaCl}$ solution; however, the fentanyl solubility in aqueous solution is limited $(0.2 \mathrm{mg} / \mathrm{mL}$ in water). Therefore, fentanyl was dissolved in $10 \%$ dimethyl sulfoxide, $10 \%$ Tween 80 , and saline for drug administration. Heroin $^{24}$ and fentanyl haptens ${ }^{11}$ were synthesized per our literature procedure, and protein conjugation proceeded as previously described. ${ }^{23}$ Vaccines were formulated with $50 \%$ (v/ v) glycerol and $50 \mu \mathrm{g}$ of $\mathrm{CpG} /$ dose per mouse and stored at $-80{ }^{\circ} \mathrm{C}$. Immediately prior to administration, the vaccines were thawed and mixed with $0.8 \mathrm{mg}$ of alum/dose per mouse for at least half an hour.

Hapten Density Determination by Matrix-Assisted Laser Desorption Ionization. The heroin and fentanyl hapten densities on carrier proteins were assessed using MALDI-time-of-flight (matrix-assisted laser desorption ionization-ToF) and electrospray ionization-ToF mass spectrometry analysis as described in our previous publications. ${ }^{22,23}$ The immunoconjugate spectra are reported in the Supporting Information (Figures S1-S4). A summary of the results is located in Table 1.

ELISA. The serum midpoint titers were determined as reported in our previous study. ${ }^{23}$ Sera from control mice either did not contain any antibodies or showed a very minor titer against Her-BSA or Fent-BSA.

SPR to Measure Affinity Values. The binding $\mathrm{IC}_{50}$ values were acquired and analyzed by SPR over week 3 and 5 bleeds to observe the effect of subsequent vaccination on affinity to free heroin (6-AM) or fentanyl (or analogues) as previously reported. ${ }^{11,23}$ Analogues of fentanyl were run against week 5 bleeds from Fent and Fent + Her vaccination groups.

Antinociceptive Behavioral Assays. Mice were tested for cumulative drug response in supraspinal (hot plate) and spinal (tail flick) behavioral tests as described in our prior study. ${ }^{21,23}$ For $10 \%$ fentanyl to heroin, the following doses were used for fentanyl and heroin: $0.025,0.05,0.1,0.15,0.25$, 0.45 , and $0.85 \mathrm{mg} / \mathrm{kg}$ and $0.25,0.5,1.0,1.5,2.5,4.5$, and 8.5 $\mathrm{mg} / \mathrm{kg}$, respectively.

\section{ASSOCIATED CONTENT}

Supporting Information

The Supporting Information is available free of charge on the ACS Publications website at DOI: 10.1021/acsomega.8b01478.

Synthesis of fentanyl hapten, immunoconjugate characterization by MALDI-ToF, mouse body weight measurements, injection site reactions, and MPE dose curves (PDF)

\section{AUTHOR INFORMATION}

\section{Corresponding Author}

*E-mail: kdjanda@scripps.edu.

ORCID

Candy S. Hwang: 0000-0003-2826-4078 
Lauren C. Smith: 0000-0002-4290-3262

Kim D. Janda: 0000-0001-6759-4227

\section{Present Addresses}

${ }^{\S}$ Department of Chemistry, Southern Connecticut State University, 501 Crescent St, New Haven, CT 06515, USA.

"Faculty of Pharmaceutical Sciences, Tohoku Medical and Pharmaceutical University, Komatsushima 4-4-1, Aoba-ku, Sendai, 981-8558, Japan.

\section{Author Contributions}

C.S.H. and L.C.S. contributed equally. C.S.H., Y.N., B.Z., B.E., and K.D.J contributed to designing the research strategy and experimental plan. Y.N. synthesized heroin and fentanyl haptens. L.C.S. conjugated, characterized, and formulated immunoconjugate vaccines. C.S.H. and L.C.S. handled all animal experiments including bleeds, vaccination, weighing, and antinociception assays. L.C.S. and B.E. ran the ELISA experiments. B.Z. ran the SPR experiments. C.S.H., L.C.S., Y.N., and B.Z. analyzed the data. C.S.H. wrote the manuscript and the Supporting Information. L.C.S. made all figures, tables, and TOC graphic in the manuscript and the Supporting Information. C.S.H., B.E., and K.D.J. edited the manuscript. All authors have given approval to the final version of the manuscript.

\section{Funding}

This work was supported by National Institutes of Health Grants F32AI126628 (C.S.H.) and UH3DA041146 (K.D.J.).

\section{Notes}

The authors declare no competing financial interest.

\section{ACKNOWLEDGMENTS}

The manuscript is \#29703 from The Scripps Research Institute.

\section{ABBREVIATIONS}

6-AM, 6-acetylmorphine; CpG ODN, cytosine-phosphodiester-guanine oligodeoxynucleotide; TT, tetanus toxoid; $\mathrm{KLH}$, keyhole limpet hemocyanin; MALDI-ToF MS, matrix-assisted laser desorption ionization time-of-flight mass spectrometry; iv, intravenous; ip, intraperitoneal; sc, subcutaneous; SPR, surface plasmon resonance

\section{REFERENCES}

(1) Ostling, P. S.; Davidson, K. S.; Anyama, B. O.; Helander, E. M.; Wyche, M. Q.; Kaye, A. D. America's Opioid Epidemic: a Comprehensive Review and Look into the Rising Crisis. Curr. Pain Headache Rep. 2018, 22, 32.

(2) Vadivelu, N.; Kai, A. M.; Kodumudi, V.; Sramcik, J.; Kaye, A. D. The Opioid Crisis: a Comprehensive Overview. Curr. Pain Headache Rep. 2018, 22, 16.

(3) United States Drug Enforcement Administration. National Heroin Threat Assessment Summary-Updated. DEA Intelligence Report No. DEA-DCT-DIR-031-16, 2016.

(4) Hull, M. J.; Juhascik, M.; Mazur, F.; Flomenbaum, M. A.; Behonick, G. S. Fatalities associated with fentanyl and coadministered cocaine or opiates. J. Forensic Sci. 2007, 52, 1383-1388.

(5) Arens, A. M.; van Wijk, X. M.; Vo, K. T.; Lynch, K. L.; Wu, A. H.; Smollin, C. G. Adverse Effects From Counterfeit Alprazolam Tablets. JAMA Intern. Med. 2016, 176, 1554-1555.

(6) Solis, E., Jr.; Cameron-Burr, K. T.; Kiyatkin, E. A. Heroin Contaminated with Fentanyl Dramatically Enhances Brain Hypoxia and Induces Brain Hypothermia. eNeuro 2017, 4, e0323-17.2017.
(7) van Dorp, E. L. A.; Yassen, A.; Dahan, A. Naloxone treatment in opioid addiction: the risks and benefits. Expert Opin. Drug Saf. 2007, $6,125-132$.

(8) Marsden, J.; Stillwell, G.; Hellier, J.; Brown, A. M.; Byford, S.; Kelleher, M.; Kelly, J.; Murphy, C.; Shearer, J.; Mitcheson, L. Effectiveness of adjunctive, personalised psychosocial intervention for non-response to opioid agonist treatment: Study protocol for a pragmatic randomised controlled trial. Contemp. Clin. Trials 2017, 53, $36-43$.

(9) Gossop, M.; Marsden, J.; Stewart, D.; Kidd, T. The National Treatment Outcome Research Study (NTORS): 4-5 year follow-up results. Addiction 2003, 98, 291-303.

(10) Schlosburg, J. E.; Vendruscolo, L. F.; Bremer, P. T.; Lockner, J. W.; Wade, C. L.; Nunes, A. A. K.; Stowe, G. N.; Edwards, S.; Janda, K. D.; Koob, G. F. Dynamic vaccine blocks relapse to compulsive intake of heroin. Proc. Natl. Acad. Sci. U.S.A. 2013, 110, 9036-9041.

(11) Bremer, P. T.; Kimishima, A.; Schlosburg, J. E.; Zhou, B.; Collins, K. C.; Janda, K. D. Combatting Synthetic Designer Opioids: A Conjugate Vaccine Ablates Lethal Doses of Fentanyl Class Drugs. Angew. Chem., Int. Ed. Engl. 2016, 55, 3772-3775.

(12) Gooyit, M.; Miranda, P. O.; Wenthur, C. J.; Ducime, A.; Janda, K. D. Influencing Antibody-Mediated Attenuation of Methamphetamine CNS Distribution through Vaccine Linker Design. ACS Chem. Neurosci. 2016, 8, 468-472.

(13) Sulima, A.; Jalah, R.; Antoline, J. F. G.; Torres, O. B.; Imler, G. H.; Deschamps, J. R.; Beck, Z.; Alving, C. R.; Jacobson, A. E.; Rice, K. C.; Matyas, G. R. A Stable Heroin Analogue That Can Serve as a Vaccine Hapten to Induce Antibodies That Block the Effects of Heroin and Its Metabolites in Rodents and That Cross-React Immunologically with Related Drugs of Abuse. J. Med. Chem. 2018, 61, 329-343.

(14) Kimishima, A.; Wenthur, C. J.; Eubanks, L. M.; Sato, S.; Janda, K. D. Cocaine Vaccine Development: Evaluation of Carrier and Adjuvant Combinations That Activate Multiple Toll-Like Receptors. Mol. Pharm. 2016, 13, 3884-3890.

(15) Pravetoni, M.; Raleigh, M. D.; Le Naour, M.; Tucker, A. M.; Harmon, T. M.; Jones, J. M.; Birnbaum, A. K.; Portoghese, P. S.; Pentel, P. R. Co-administration of morphine and oxycodone vaccines reduces the distribution of 6-monoacetylmorphine and oxycodone to brain in rats. Vaccine 2012, 30, 4617-4624.

(16) Li, Q.-Q.; Luo, Y.-X.; Sun, C.-Y.; Xue, Y.-X.; Zhu, W.-L.; Shi, H.-S.; Zhai, H.-F.; Shi, J.; Lu, L. A morphine/heroin vaccine with new hapten design attenuates behavioral effects in rats. J. Neurochem. 2011 $119,1271-1281$.

(17) Jalah, R.; Torres, O. B.; Mayorov, A. V.; Li, F.; Antoline, J. F. G.; Jacobson, A. E.; Rice, K. C.; Deschamps, J. R.; Beck, Z.; Alving, C. R.; Matyas, G. R. Efficacy, but not antibody titer or affinity, of a heroin hapten conjugate vaccine correlates with increasing hapten densities on tetanus toxoid, but not on CRM197 carriers. Bioconjugate Chem. 2015, 26, 1041-1053.

(18) Miller, M. L.; Moreno, A. Y.; Aarde, S. M.; Creehan, K. M.; Vandewater, S. A.; Vaillancourt, B. D.; Wright, M. J.; Janda, K. D.; Taffe, M. A. A methamphetamine vaccine attenuates methamphetamine-induced disruptions in thermoregulation and activity in rats. Biol. Psychiatry 2013, 73, 721-728.

(19) Hoogsteder, P. H. J.; Kotz, D.; van Spiegel, P. I.; Viechtbauer, W.; van Schayck, O. C. P. Efficacy of the nicotine vaccine 3'-AmNicrEPA (NicVAX) co-administered with varenicline and counselling for smoking cessation: a randomized placebo-controlled trial. Addiction 2014, 109, 1252-1259.

(20) Stowe, G. N.; Vendruscolo, L. F.; Edwards, S.; Schlosburg, J. E.; Misra, K. K.; Schulteis, G.; Mayorov, A. V.; Zakhari, J. S.; Koob, G. F.; Janda, K. D. A vaccine strategy that induces protective immunity against heroin. J. Med. Chem. 2011, 54, 5195-5204.

(21) Bremer, P. T.; Schlosburg, J. E.; Lively, J. M.; Janda, K. D. Injection route and TLR9 agonist addition significantly impact heroin vaccine efficacy. Mol. Pharm. 2014, 11, 1075-1080.

(22) Hwang, C. S.; Bremer, P. T.; Wenthur, C. J.; Ho, S. O.; Chiang, S. M.; Ellis, B.; Zhou, B.; Fujii, G.; Janda, K. D. Enhancing Efficacy 
and Stability of an Antiheroin Vaccine: Examination of Antinociception, Opioid Binding Profile, and Lethality. Mol. Pharm. 2018, 15, $1062-1072$.

(23) Hwang, C. S.; Smith, L. C.; Natori, Y.; Ellis, B.; Zhou, B.; Janda, K. D. Efficacious Vaccine against Heroin Contaminated with Fentanyl. ACS Chem. Neurosci. 2018, 9, 1269-1275.

(24) Bremer, P. T.; Schlosburg, J. E.; Banks, M. L.; Steele, F. F.; Zhou, B.; Poklis, J. L.; Janda, K. D. Development of a Clinically Viable Heroin Vaccine. J. Am. Chem. Soc. 2017, 139, 8601-8611.

(25) United States Drug Enforcement Agency. Fentanyl: a briefing guide for first responders; US Department of Justice, Drug Enforcement Administration: Washington, DC, 2017.

(26) Rodda, L. N.; Pilgrim, J. L.; Di Rago, M.; Crump, K.; Gerostamoulos, D.; Drummer, O. H. A Cluster of Fentanyl-Laced Heroin Deaths in 2015 in Melbourne, Australia. J. Anal. Toxicol. 2017, 41, 318-324.

(27) Moreno, A. Y.; Azar, M. R.; Warren, N. A.; Dickerson, T. J.; Koob, G. F.; Janda, K. D. A critical evaluation of a nicotine vaccine within a self-administration behavioral model. Mol. Pharm. 2010, 7, 431-441.

(28) Kimishima, A.; Wenthur, C. J.; Zhou, B.; Janda, K. D. An Advance in Prescription Opioid Vaccines: Overdose Mortality Reduction and Extraordinary Alteration of Drug Half-Life. ACS Chem. Biol. 2017, 12, 36-40. 